Members can and do share this knowledge locally through training sessions, but professional networking through publishing in Notice Board or a professional journal can reach thousands rather than dozens of practitioners.

The next time you hear the words: 'You should write that up', accept the compliment, read Margaret's article and then find a strategy that fits your circumstances and Get Publishing!

\title{
You should write that up: Getting practitioners started on writing for publication
}

\author{
Margaret McKenzie
}

This article is based upon a workshop presented at the recent ANZSW conference by Margaret McKenzie and Raylee Kane (Co-editors of Social Work Review) which was designed to encourage and enable social work practitioners to write for publication (preferably in the New Zealand Social Work Review). ${ }^{1}$

\section{Introduction}

The Social Work Review Editorial team and Board is keen to maintain a practice focus to the journal. Many overseas journal editors applaud the retention of practitioner involvement and practice-based writing which the journal has achieved to date. This key focus can only continue if practitioners do write for us!

The article will:

a) Encourage those practitioners who would like to get their work published but are inexperienced and unsure how to go about achieving this goal.

b) Encourage those who have not really considered writing up their work but who have had people say 'you should write that up', but wonder how to get started.

The aim is to provide a mixture of information and practical exercises which will serve as potential starters in the writing process.

The article comprises three parts:

- Part One, a discussion of some of the reasons for writing and publishing on social work practice for the journal (what we want from you)

1 Developed after attendance at a publishing workshop presented by Dr Sally Brown, University of Northumbria, Otago Polytechnic, Dunedin, June, 1998. 
- Part Two, briefly indicates some of the nuts and bolts (what's really required, do's and don'ts)

- Part Three, provides some practical exercises/ideas which can be worked through in getting started with the writing process (you have got something to say)

The goal is to enable some, if not all readers to develop and begin to implement a plan to write-up for publication a piece of practice based work. While a 'reading about' article can never have the same impetus as a 'doing' workshop, it is hoped that those practitioners who were unable to attend the conference but with an interest in writing for the journal can obtain the essence of the workshop information. This article recognises that many people come unstuck at the point of doing, rather than the point of talking about and we hope to enable readers to progress some way along the track of planning and constructing the bones of a piece of writing which can be submitted for publication.

This article is designed to follow on and complement an excellent article from the previous editorial team who also wished to encourage and assist with the development of the journal (Bradley, Ellis, Munford, Nash and Sayers, 1995). While emphasising the practicalities, the 'nuts and bolts' of publishing from an editorial view, Bradley et al. also provided a valuable section on getting started and the fear of writing, which is drawn on in part one.

A step by step series of exercises which can be worked through either individually or in a group situation, provides the practical guidance to getting started in part three. Working through these will enable you to move beyond intention and into action.

However an article alone may not be enough to realise our ambition of continuing the journals strong record of publishing practice-based research. The journal editors and board are always willing to be contacted and consulted with ideas and initial action for potential articles. Do approach us, do contact us, do consult, whether by mail or phone.

\section{Part One: What we want from you}

The importance of writing up practice.

First,

- Why do it? And

- Why practice based writing is important.

\section{Why do it?}

Social workers are busy people who pride themselves on their active role in social and community work practice, thus taking time to sit back, to reflect and write on these experiences can be perceived as a luxury rather than a necessary part of the social work task.

Indeed much of the material which does reach publication in overseas journals is sourced from academics, those who are primarily teachers and researchers of social work and who are required to publish, caught up in the 'publish or perish' game rather than active grassroots practitioners.

Many reasons can and have been put forward as rationales for writing or indeed for not writing. Those for not writing tend to be associated with the difficulties of getting started, 
and are commonly summed up under the heading Fear (Day, 1996: 11). fears:

Bradley, et al. (1995: 14), raise and offer pertinent rejoinders to the following typical

...nothing I say is useful and no one will read what I have to say....

...I don't see myself as a writer. I have no confidence to do this...

...How could I write something other than a case note or record?...

The strategies for countering these fears include:

- Test ideas and drafts on trusted others first.

- Remember what may be commonplace practice to you, may be innovative to others (and that New Zealanders are well known for innovation).

- Begin with your own experience, something you know thoroughly.

- Start small, for example, a book review or a commentary rather than a full-scale critical analysis.

- Take time, don't expect perfection first time and timetable writing into your daily / weekly activities and goals.

- Do check out ethical issues and permission before you start.

- Can you write under your agency auspices or should it be within another group such as a rights or professional group to which you are affiliated?

Overall the rejoinder to why write about practice, emphasises that sound and ethical practice can best be developed through such sharing, discussion, reflection and clarification that can take place within the forum of a journal article. In addition public discussion of programme and practice initiatives enables transparency and accountability and forms a strong basis for developing empowering practice.

\section{Why practice based writing is important}

Maintaining a balance of writing contributed by practitioners and academics, keeps and strengthens the developmental links in social work, as it ensures that social work practice remains connected and relevant to everyday reality.

Be aware that there is a need for publishing in social work which encompasses:

- A need for research and knowledge building in social work,

- A need for local, regional, national literature, for culture specific literature as well as international,

- An indication of the variety and breadth of social work domain in Aotearoa New Zealand, not a narrow/closed set of topics.

Writing for a journal publication which is read by practitioners, academics, researchers and students within a profession enables a research/knowledge building/practice/action dynamic for social work which can act to;

- Incorporate new developments in practice

- Monitor that practice

- Review and evaluate that practice

- Share knowledge with a wider audience

- Enable feedback

- Further develop practice by incorporation of this feedback. 


\section{Part Two: What's really required, do's and don'ts}

It is crucial when writing for publication to refer to the information for potential contributors which is provided by journals. This information will clearly indicate both the particular process followed for a journal and stipulate their 'in house' guidelines for the preparation and submission of material. ${ }^{2}$

Always consult these sections of a publication you are considering submitting to and ensure you have met their requirements. Simply meeting these base guidelines can ensure your material receives more than a cursory glance, rather than being returned largely unread simply because you did not meet base standards.

Remember they have been provided as guidelines, familiarise yourself with them. They are to help not to block you meeting standards.

\section{Other practical tips on getting published}

Be:

- Readable.

- Current.,

- Interesting.

- Practice focused, not purely academic.

- Cutting edge/developing fields.

- Succinct, not turgid.

- Clear, well-organised.

- Logical.

- Focused not muddled or waffling.

- Reader friendly (watch jargon, abbreviations).

- Positive rather than negative.

\section{Always}

- Check, double check and check again the detailing of the references cited.

\section{Part Three: You have got something to say}

This section provides a set of three exercises which can be worked through individually, or in a partner or group situation. Primarily for those with little of no publication record, but with a desire to attain one, they are designed to enable the reader/participant to gain confidence in beginning writing, by demonstrating that the resource to begin is in fact present, but as yet 'untapped'. The exercises enable you to 'tap' that resource and focus the writing process. They are of course brief, and may be thought as something of a whirlwind tour into the mystery of writing!

Task One

Why do you want to write? Why should you write? What are the likely effects?

2 See the Guidelines for Contributors, page 98 of this journal. 
List $2-5$ benefits of you getting published. Benefits are things that mean something to you, for example:

Personal: I'd like to see my name in print in a well respected journal.

Professional: Career benefits, writing about my work will bring me exposure and recognition, could bring me new work. Add to my C.V., publicise the work I've been doing, emphasis my interests/knowledge in a specialist field. Benefits to my organisation. Benefits to the profession.

This task, listing your objectives sets down the particular reasons you choose to write, and has relevance to you especially. It can also form a base you can return to perhaps as a reminder when the going gets rough, and for review and alteration as your writing ambitions expand.

\section{Task Two:}

What do I plan to write about: Getting a starting point.

Write down (at first very briefly, twenty words or less is suggested);

1. What do you want to say? What is the article/paper about? E.g. the purpose of this paper is to ........ My intention is to ........

(Show, demonstrate, present, synthesise, explore, review, discuss, identify), then.

2. Note how you will do this ........ (By illustration with case examples ......., by reviewing the current literature........, By describing the findings of a project carried out.......).

Congratulations, you have just written your opening paragraph! These two paragraphs frame your article opening section.

\section{Task Three}

Why will the reader want to hear about this (implications)? Why does it matter? The 'So what?' question.

This task is designed to cover the question what will the reader in your field learn from your paper? Take away to think about? How might they apply the material in your paper? What should they think about when they have finished reading your paper?

- Again, write down in twenty words or less

(the implications of this are ...... these findings are of value because this will be of interest to because further questions which could be explored are these ideas could be applied in the following manner ......... The significance of this ........)

Don't forget to review your purpose / intention statement. Have you delivered what you said you would?

Congratulations, you have now written your closing paragraph. ${ }^{3}$

This outlining/planning of both the opening and closing sections of your paper gives you the base to attack the middle or substantive section of the work.

Task One -Three are developed from points expressed in Day (1996). 
The middle section: The middle or substantive section of a paper takes shape and contains content according to the decisions you have made with regard to the opening/introduction paragraph/s where you have laid out your intentions and the closing/concluding paragraphs where you have indicated the implications of your material. It is, of course, subject dependent and so the individual detail cannot be addressed within this article. But having developed these introduction/purpose and conclusion/implication statements, use these next as the key to assist in the guiding and directing of the writing content for the substantive section.

\section{Conclusion}

These processes are keys to get started on your writing for publication. The exercises should enable the following to have taken place:

- Clarified the targeting of the writing,

- Crystallised the points you want to make (purpose and implications),

- Demonstrated writing to a time deadline (they are always unreasonable),

- Demonstrated writing to a brief (what they ask),

- Demonstrated writing to a length limit (you will always have more to say),

- Justifying yourself (knowing the rational for your writing; both self benefits and adding to knowledge base of field),

- Practised framing/writing and reframing/rewriting the same material to improve it,

- Practised planning and structuring,

- Demonstrated the advantages of brainstorming, thinking fast and mind mapping techniques in this situation.

In summary as with any piece of work, an article for publication essentially comprises three sections, the beginning or introduction, the middle or substantive content and the end or implications and conclusion. The exercises have been designed to get you started on preparing brief drafts of each of these sections.

A final task is included to ensure the hard work to date does not remain unfinished.

\section{Task Four}

Where to from here? What will you do next?

Make a list of three actions you will take as a result of completing these tasks (e.g., I read the article, I did the tasks, I developed a paper, I sent it off, I got it published).

\section{References}

Bradley, J., Ellis, G., Munford, R., Nash, M., \& Sayers, J. (1995). Partnerships in publishing. Social Work Review, $\operatorname{VII}(4), 14-16$.

Brown, S. et al. (1998). 500 tips for getting published. London: Kogan Page.

Day, A. (1996). How to get research published in journals. Aldershot: Gower. 